\title{
PADRÕES DE MINIESTACAS E SAZONALIDADE NA PRODUÇÃO DE MUDAS CLONAIS DE Eucalyptus grandis HILL X E. urophylla S. T. BLACK ${ }^{1}$
}

\author{
Cibele Chaves Souza ${ }^{2}$, Aloisio Xavier ${ }^{3}$, Fernando Palha Leite $^{4}$, Reynaldo Campos Santana ${ }^{5}$ e Hélio \\ Garcia Leite ${ }^{3}$
}

\begin{abstract}
RESUMO - Este estudo teve por objetivo avaliar a influência de diferentes padrões de miniestacas no enraizamento e produção de mudas do híbrido do Eucalyptus grandis Hill x E. urophylla S.T. Black no verão e no inverno. Experimentos com cinco clones e 12 diferentes padrões de miniestacas foram conduzidos em duas épocas do ano (verão e inverno). A sobrevivência e enraizamento das miniestacas foram avaliados na saída da casa de vegetação e na saída da casa de sombra e, a pleno sol, a sobrevivência, a altura, o diâmetro do colo, o peso de massa seca da parte aérea e o da raiz. Os resultados indicaram que a manutenção das folhas é importante para o enraizamento de miniestacas de Eucalyptus grandis $\mathrm{x}$ E. urophylla, e as folhas basais obtiveram maiores valores de enraizamento. Mudas produzidas no verão, utilizando miniestacas de $10 \mathrm{~cm}$ de tamanho, tiveram maior crescimento. A metodologia de não redução das folhas mostrou-se procedimento adequado para produção de mudas nas duas épocas do ano.
\end{abstract}

Palavras-chave: Miniestaquia, Enraizamento, Silvicultura clonal.

\section{PATTERNS OF MINI-CUTTINGS AND SEASONALITY IN SEEDLINGS PRODUCTION Eucalyptus grandis HILL X E. urophylla HYBRID S. T. BLACK}

\begin{abstract}
The present study aimed to evaluate the influence of different patterns of mini-cuttigs on rooting and production of hybrid Eucalyptus grandis Hill x E. urophylla S. T. Black hybrid in summer and winter. Experiments with five clones and 12 different patterns of mini-cuttings were conducted in two seasons (summer and winter). The survival and rooting were evaluated ate the output greenhouse and output of the shade and in full sun, survival, height, diameter, the dry weight of shoot and root. The results indicated that the maintenance of leaves is important for rooting mini-cuttings of Eucalyptus grandis Hill $x \boldsymbol{E}$. urophylla $S$. T. Black hybrids, and the basal leaves had higher values of rooting. Seedlings produced in summer, using cuttings of $10 \mathrm{~cm}$ in size, had higher growth's methodology leaves no reduction procedure proved suitable for seedling production in both seasons.
\end{abstract}

Keywords: Mini-cutting technique, Rooting, Clonal forestry.

\section{INTRODUÇÃO}

A produção de mudas clonais de eucalipto (Eucalyptus spp.) no Brasil iniciou-se no final da década de 1970, com a técnica de propagação vegetativa pela estaquia, sendo esta a base para o desenvolvimento das atuais técnicas de microestaquia e miniestaquia (XAVIER et al., 2009). A técnica de miniestaquia tem sido a mais utilizada para produção comercial de mudas do gênero Eucalyptus pelas empresas, devido ao ganho

\footnotetext{
${ }^{1}$ Recebido em 24.08.2012 aceito para publicação em 19.12.2012.

${ }^{2}$ Programa de Pós Graduação em Ciência Florestal da Universidade Federal de Viçosa, Minas Gerais, Brasil. E-mail: <souza.cc24@yahoo.com.br>.

${ }^{3}$ Departamento de Engenharia Florestal, Universidade Federal de Viçosa, Viçosa, Minas Gerais, Brasil. E-mail: <xavier@ ufv.br> e<hgleite@ufv.br>.

${ }^{4}$ Pesquisador na Celulose Nipo-Brasileira, CENIBRA, Minas Gerais. E-mail: <fernando.leite@ cenibra.com.br>.

${ }^{5}$ Departamento de Engenharia Florestal, Universidade Federal dos Vales do Jequitinhonha e Mucuri, Diamantina, Minas Gerais, Brasil. E-mail: <silviculturaufvjm@yahoo.com.br>.
} 
em percentuais e qualidade do enraizamento, ligados, principalmente, ao fato de utilizar estacas apicais mais juvenis e conseguir melhor controle das condições hídricas, nutricionais e fitossanitárias das plantas fornecedoras de propágulos (TITON et al., 2003; ASSIS et al., 2004).

Convencionou-se, na miniestaquia de eucalipto (Eucalyptus spp.), a utilização de propágulos vegetativos medindo entre 4 e $8 \mathrm{~cm}$, com dois pares de folhas reduzidas à metade ou proporcionalmente ao tamanho da estaca (XAVIER et al., 2009) ou, ainda, pelo menos a um terço de seu tamanho (ALFENAS et al., 2009). A redução das folhas está condicionada à cultura herdada da técnica de macroestaquia, cujos objetivos são diminuir a área de transpiração e evitar o efeito guarda-chuva, definido por Alfenas et al. (2009) como barreira física proporcionada pelas folhas das estacas ou miniestacas, impedindo o molhamento do substrato. De acordo com esses mesmos autores, o corte das folhas pode ser porta para a entrada de fungos durante a fase de enraizamento devido a injúrias causadas nas folhas das (mini)estacas.

Trabalhos realizados por Santana et al. (2010) com clones de Eucalyptus urophylla S.T. Blake demonstraram que a manutenção das folhas inteiras nas miniestacas produz resultados superiores de altura, peso de massa seca da parte aérea e peso de massa seca da raiz para a maioria dos clones estudados e não causa o efeito guarda-chuva.

A manutenção das folhas ou de pelo menos parte delas é importante para o processo de enraizamento, devido à produção de carboidratos resultantes da fotossíntese e de auxinas produzidas pelas folhas e gemas apicais essenciais ao enraizamento (TAIZ; ZEIGER, 2004; XAVIER et al., 2009; HARTMMAN et al., 2011). A biossíntese da auxina está relacionada a regiões meristemáticas e órgãos jovens, como folhas de rápido crescimento, gemas apicais, pontas de raízes e inflorescências em desenvolvimento, com predominância de transporte ápice-base, observando-se redução de sua concentração do topo para a base das plantas (TAIZ; ZEIGER, 2004). Para Pacheco e Franco (2008), a retenção das folhas de açoita-cavalo (Litehea divaricata Mart) favorece a sobrevivência e enraizamento não só por serem locais de síntese de carboidratos e auxinas, mas pela produção de alguns compostos fenólicos, que também são sintetizados na parte aérea das plantas. Esses mesmos autores citaram que compostos fenólicos, como é o caso dos ácidos cafeico, catecol e clorogênico, interagem com as auxinas, induzindo a iniciação das raízes.

Para híbridos de Eucalyptus grandis Hill x E. resinífera Smith, o melhor resultado de enraizamento foi obtido em miniestacas com quatro pares de folhas (VENDEMIATTI et al., 2009). Em sua grande maioria, a presença de folhas é fundamental para o enraizamento, fato evidenciado por pesquisas com diferentes estacas de cedro-rosa (Cedrela fissilis Vellozo) (XAVIER et al., 2003), açoita-cavalo (Luehea divaricata) (PACHECO; FRANCO, 2008) e oliveira (Olea europaea L.) (PIO et al., 2005). Em algumas espécies, a ausência de folhas em estacas pode ajudar a brotação, como encontrado em figueira (Ficus carica L.) (NOGUEIRA et al., 2007). $\mathrm{O}$ fato de estacas sem folhas conseguirem melhores resultados de enraizamento pode ser devido, de acordo com Nogueira et al. (2007), provavelmente a um alto conteúdo endógeno de auxina nas estacas.

As técnicas de propagação vegetativa evoluíram com o intuito de aumentar a rizogênese, que é influenciada por vários fatores, entre os quais a espécie, o tipo de estaca (BORGES et al., 2011), a juvenilidade dos brotos, a época de coleta (ZUFFELLATO-RIBAS; RODRIGUES, 2001; HARTMANN etal., 2011; FERREIRA et al., 2004), a presença de gemas e, ou, folhas, injúrias, balanço hormonal, presença de inibidores, condições nutricionais e hídricas da planta doadora de propágulos, constituintes do substrato e estresses ambientais (HIGASHI et al., 2000; ASSIS et al., 2004; XAVIER et al., 2009; ALFENAS et al., 2009).

Nesse contexto, o objetivo deste trabalho foi avaliar a influência de diferentes padrões de miniestacas no enraizamento e produção de mudas de híbridos de Eucalyptus grandis x E. urophylla no verão e no inverno.

\section{MATERIAL E MÉTODOS}

O trabalho foi desenvolvido no viveiro florestal da empresa Celulose Nipo-Brasileira S.A. - Cenibra, localizada no Município de Belo Oriente, Minas Gerais. O clima da região é do tipo Cwa (subtropical, chuvoso e mesotérmico), segundo a classificação de Köppen. As coordenadas são $19^{\circ} 18^{\prime} 23$ ' $\mathrm{S}$ de latitude e 42 $22^{\circ} 46^{\prime \prime} \mathrm{O}$ de longitude, com altitude média de $240 \mathrm{~m}$. A região é caracterizada por ter uma estação quente e úmida e uma fria e seca. Por esse motivo, o trabalho foi realizado no período de 3 de dezembro de 2010 a 2 de fevereiro 
de 2011 (verão) e 18 de maio a 18 de julho de 2011 (inverno). No verão houve precipitação total de 546 $\mathrm{mm}$, temperatura média de $25^{\circ} \mathrm{C}$, com máxima média de $35^{\circ} \mathrm{C}$ e mínima média de $19^{\circ} \mathrm{C}$ e umidade relativa do ar média de $76 \%$. Já no inverno a precipitação total foi de $85 \mathrm{~mm}$, a temperatura média de $20^{\circ} \mathrm{C}$ com máxima média de $31{ }^{\circ} \mathrm{C}$ e mínima média de $11^{\circ} \mathrm{C}$ e umidade relativa do ar média de $80 \%$.

Foram utilizados cinco clones comerciais de Eucalyptus grandis x E. urophylla (C1, C2, C3, C4 e C5), definidos em função da capacidade de enraizamento. O clone $\mathrm{C} 1$ foi considerado de fácil enraizamento, com percentual médio acima de $90 \%$, o clone C5, de maior dificuldade de enraizamento, com percentual médio abaixo de $80 \%$, e os outros três clones (C2, C3 e C4) foram considerados intermediários, com percentual médio de enraizamento entre 80 e $90 \%$, dados disponibilizados pela empresa.

\subsection{Minijardim Clonal}

O minijardim clonal foi constituído por canaletas suspensas de alvenaria, preenchidas com brita $\mathrm{n}^{\circ} 2$ no fundo e areia lavada até a borda, instalado sob um sistema de cobertura retrátil. As minicepas foram produzidas por meio do enraizamento de miniestacas. Após plantio das minicepas nas canaletas, elas tiveram seus ápices podados a uma altura de $10 \mathrm{~cm}$, fornecendo, a partir daí, as miniestacas para a realização do experimento.

A irrigação e fertilização mineral do minijardim clonal foram efetuadas utilizando-se um sistema automatizado de fertirrigação por gotejamento, acionado de três a quatro vezes por dia, de acordo com a temperatura do dia, variando de 0 em dias frios a $7 \mathrm{~mm} \mathrm{~m}^{-2} \mathrm{dia}^{-1} \mathrm{em}$ dias muito quentes, por um período de $6 \mathrm{~min}$. A solução nutritiva foi composta por nitrato de cálcio $\left(0,92 \mathrm{~g} \mathrm{~L}^{-1}\right)$, cloreto de potássio $\left(0,24 \mathrm{~g} \mathrm{~L}^{-1}\right)$, nitrato de potássio $\left(0,14 \mathrm{~g} \mathrm{~L}^{-1}\right)$, fosfato monoamônio $\left(0,10 \mathrm{~g} \mathrm{~L}^{-1}\right)$, sulfato de magnésio $\left(0,36 \mathrm{~g} \mathrm{~L}^{-1}\right)$, hidroferro $\left(0,04 \mathrm{~g} \mathrm{~L}^{-1}\right)$, ácido bórico (2,80 $\left.\mathrm{mg} \mathrm{L}^{-1}\right)$, sulfato de zinco $\left(0,48 \mathrm{mg} \mathrm{L}^{-1}\right)$, sulfato de manganês $\left(1,12 \mathrm{mg} \mathrm{L}^{-1}\right)$, sulfato de cobre $\left(0,10 \mathrm{mg} \mathrm{L}^{-1}\right)$ e molibdato de sódio $\left(0,04 \mathrm{mg} \mathrm{L}^{-1}\right)$. O excesso da solução nutritiva era drenado para o fundo da canaleta e retornava, por meio de um sistema de tubulações, para a caixa de armazenamento de solução, monitorada regularmente e trocada a cada sete dias. Diariamente, eram monitorados a Ec (condutividade elétrica) e o pH da solução, visando manter a Ec entre 1,0 e $1,5 \mathrm{mS} \mathrm{cm}^{-1}$ e o pH da solução entre 5,5 e 6,5 .

\subsection{Obtenção, preparo e estaqueamento das miniestacas}

As miniestacas utilizadas neste trabalho foram colhidas e preparadas, como informado na Tabela 1 e mostrado na Figura 1.

Para manter as condições de turgescência do material vegetal, as miniestacas foram acondicionadas em caixas de isopor, pulverizadas com água utilizando um pulverizador manual, em intervalos de tempos inferiores a $5 \mathrm{~min}$, até o estaqueamento.

As miniestacas foram plantadas em tubetes com $12 \mathrm{~cm}$ de comprimento e $55 \mathrm{~cm}^{3}$ de capacidade, previamente desinfestados em água quente a $70{ }^{\circ} \mathrm{C} /$ 1 min (ALFENAS et al., 2009) e contendo substrato composto por $50 \%$ de vermiculita e $50 \%$ de casca de arroz carbonizada. A adubação foi a seguinte: $7,0 \mathrm{~kg} /$ $\mathrm{m}^{3}$ de superfosfato simples, $0,695 \mathrm{~kg} / \mathrm{m}^{3}$ de sulfato de amônio, 0,208 kg/m³ de cloreto de potássio, 0,014 kg $\mathrm{m}^{-3}$ de sulfato de zinco, $0,014 \mathrm{~kg} \mathrm{~m}^{-3}$ de sulfato de cobre, $0,014 \mathrm{~kg} \mathrm{~m}^{-3}$ de sulfato de manganês e $0,021 \mathrm{~kg} \mathrm{~m}^{-3} \mathrm{de}$ ácido bórico.

O processo de enraizamento das miniestacas foi conduzido em casa de vegetação climatizada (umidade relativa do ar $\geq 80 \%$ e temperatura em torno de $27^{\circ} \mathrm{C}$ ) com permanência de 20 dias. Após esse período, as mudas foram transferidas para casa de sombra, com sombrite de $50 \%$ de redução da luminosidade, em que permaneceram por mais 11 dias; finalmente, foram transferidas para área a pleno sol até completarem 61 dias de idade.

As avaliações, tanto no verão quanto no inverno, compreenderam a sobrevivência (SCV) e enraizamento (ECV) na saída da casa de vegetação (20 dias após o estaqueamento) e na saída da casa de sombra (SCS e ECS) (30 dias após o estaqueamento), sobrevivência (SPS), altura (Alt), diâmetro do colo (DC) na área a pleno sol (50 dias após o estaqueamento) e peso de massa seca da parte aérea (PSPA) e do sistema radicular (PSRA). Para isso, foram amostradas quatro miniestacas/ repetição, considerando-se valores médios do crescimento em altura em área a pleno sol, para expedição (61 dias de idade após o estaqueamento). O PSPA e o PSRA foram obtidos por meio da secção da área limítrofe entre a parte aérea e a radicular. Posteriormente foram levadas à estufa de circulação forçada a $60^{\circ} \mathrm{C}$ até chegarem a peso constante. A avaliação do

Revista Árvore, Viçosa-MG, v.37, n.1, p.67-77, 2013 
Tabela 1 - Padrões de miniestacas de Eucalyptus grandis x E. urophylla.

Table 1 - Patterns of mini-cuttings of Eucalyptus grandis x E. urophylla hybrid.

\begin{tabular}{ll}
\hline Identificação & \multicolumn{1}{c}{ Especificações das miniestacas apicais } \\
\hline $6 \mathrm{ASR}$ & $6 \mathrm{~cm}$ de tamanho com as folhas inteiras (sem redução) \\
$10 \mathrm{ASR}$ & $10 \mathrm{~cm}$ de tamanho com as folhas inteiras (sem redução) \\
$6 \mathrm{AR}_{1 / 3}$ & $6 \mathrm{~cm}$ de tamanho com suas folhas reduzidas para $1 / 3$ do tamanho da miniestaca \\
$10 \mathrm{AR}_{1 / 3}$ & $10 \mathrm{~cm}$ de tamanho com suas folhas reduzidas para $1 / 3$ do tamanho da miniestaca \\
$6 \mathrm{AR}_{1 / 2}$ & $6 \mathrm{~cm}$ de tamanho com suas folhas reduzidas pela metade \\
$10 \mathrm{AR}$ & $10 \mathrm{~cm}$ de tamanho com suas folhas reduzidas pela metade \\
$6 \mathrm{Afi}$ & $6 \mathrm{~cm}$ de tamanho com somente o par de folhas inferior reduzidas pela metade \\
$10 \mathrm{Afi}$ & $10 \mathrm{~cm}$ de tamanho com somente o par de folhas inferiores reduzidas pela metade \\
$6 \mathrm{Afs}$ & $6 \mathrm{~cm}$ de tamanho com somente as folhas superiores \\
$10 \mathrm{Afs}$ & $10 \mathrm{~cm}$ de tamanho com somente as folhas superiores \\
$6 \mathrm{Asf}$ & $6 \mathrm{~cm}$ de tamanho sem as folhas \\
$10 \mathrm{Asf}$ & $10 \mathrm{~cm}$ de tamanho sem as folhas \\
\hline
\end{tabular}
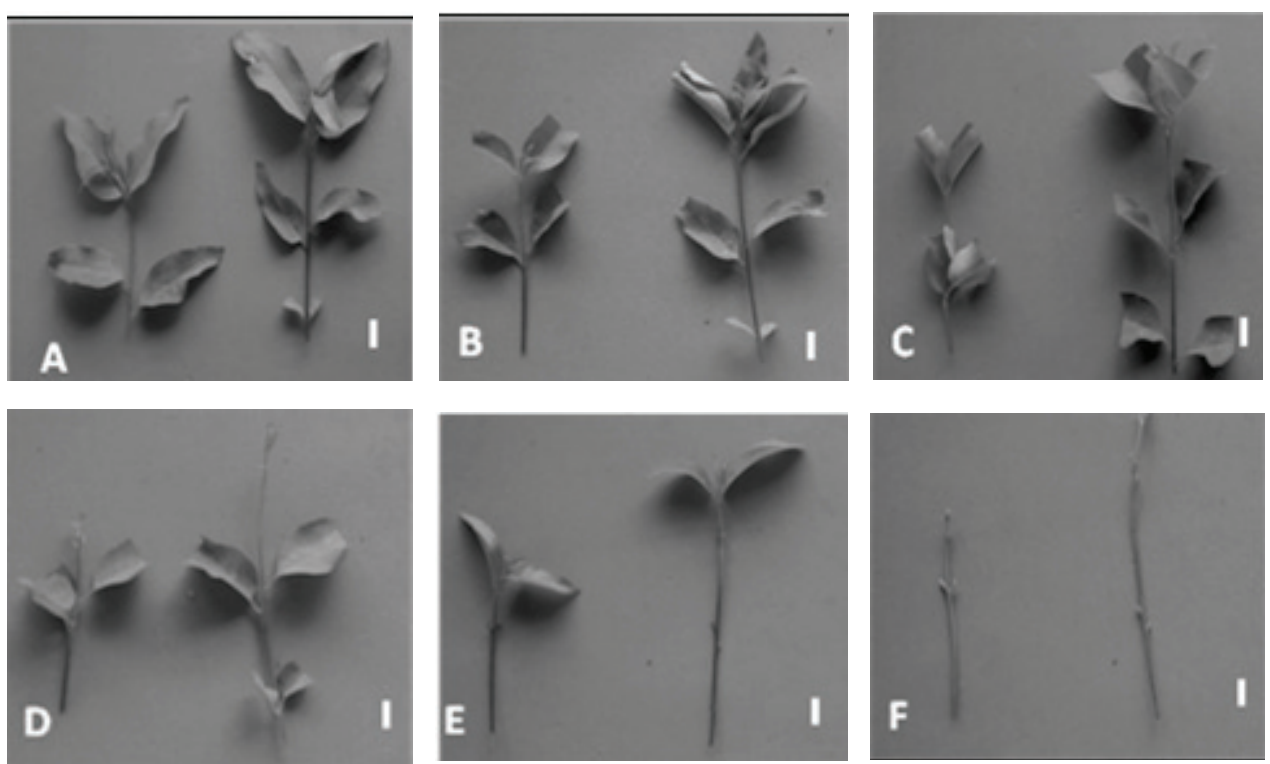

Figura 1 - Detalhes dos padrões de miniestacas apicais utilizadas. A: ASR - com 6 e $10 \mathrm{~cm}$ de tamanho com as folhas inteiras (sem redução); B: $\mathrm{AR}_{1 / 3}$ - com 6 e $10 \mathrm{~cm}$ de tamanho com suas folhas reduzidas para 1/3 do tamanho da miniestaca; $\mathrm{C}: \mathrm{AR}_{1 / 2}$ - com 6 e $10 \mathrm{~cm}$ de tamanho com suas folhas reduzidas pela metade; D: Afi - com 6 e $10 \mathrm{~cm}$ de tamanho com somente o par de folhas inferiores reduzidas pela metade; E: Afs - com 6 e $10 \mathrm{~cm}$ de tamanho com somente folhas superiores; e F: Asf - com 6 e $10 \mathrm{~cm}$ de tamanho sem as folhas. Barra $=1 \mathrm{~cm}$.

Figure 1 -Details of patterns used mini-cuttings apical. A: ASR - with 6 and $10 \mathrm{~cm}$ in size with whole leaves (without reduction); $B: A R_{1 / 3}{ }^{-}$with 6 and $10 \mathrm{~cm}$ in size as its leaves reduced to one third the size of mini-cuttings; $C: A R_{1 / 2}-$ with 6 and $10 \mathrm{~cm}$ in size with their leaves cut in half; D: Afi - with 6 and $10 \mathrm{~cm}$ in size with only the lower pair of leaves halved; E: Afs - with 6 and $10 \mathrm{~cm}$ in size with upper and F: Asf - 6 and $10 \mathrm{~cm}$ in size without the sheets. Bar $=1 \mathrm{~cm}$.

enraizamento foi determinada pela observação da emissão das raízes na extremidade inferior do tubete e pela obtenção do peso de massa seca da raiz. Para obtenção do peso da massa seca de raiz, procedeu-se à retirada do substrato com água, tomando o devido cuidado de preservar a massa radicial. Na sequência, as amostras foram levadas à estufa de circulação forçada para secar a $60{ }^{\circ} \mathrm{C}$ até peso constante.

Revista Árvore, Viçosa-MG, v.37, n.1, p.67-77, 2013 
Os dados resultantes foram submetidos à análise de variância e ao teste de Scott-Knott a 5\% de probabilidade, utilizando-se o programa estatístico R.

\section{RESULTADOS}

Os clones avaliados responderam, de maneira diferente, aos padrões de miniestacas e à época do ano. No verão, observou-se interação significativa apenas no enraizamento na saída da casa de vegetação (ECS), mas no inverno observou-se interação significativa $(\mathrm{P}<0,05)$, em quase todas as características avaliadas, exceto sobrevivência na saída da casa de sombra (SCS), altura (ALT) e peso de massa seca da raiz (PSRA).

As miniestacas sem folhas apresentaram as menores taxas de sobrevivência e de enraizamento na saída da casa de vegetação e da casa de sombra, tanto no verão quanto no inverno (Tabela 2). Nos demais tipos de miniestacas, a sobrevivência na saída da casa de vegetação e da casa de sombra foi mais elevada, considerando-se as duas épocas avaliadas, sendo as miniestacas apicais com manutenção somente das folhas novas (apicais) as que apresentaram valores mais baixos em relação a algumas características avaliadas.

No enraizamento na saída da casa de vegetação e da casa de sombra, foram observados, em média, valores inferiores nas miniestacas sem folhas (Asf) e com somente as folhas superiores (Asf). As miniestacas Afi (miniestaca apical com somente o par de folhas inferior reduzido pela metade) tiveram maior taxa de enraizamento em relação àquelas com somente as folhas superiores (Afs), principalmente no verão, não sendo necessariamente verdadeiro no inverno. Os valores observados no enraizamento no verão foram maiores do que no inverno, em todos os clones e na maioria dos tipos de miniestacas, à exceção das miniestacas Afs e do clone $\mathrm{C} 4$, que mostraram os melhores resultados de enraizamento na saída da casa de vegetação no inverno, em comparação com o verão.

Observou-se queda na sobrevivência das miniestacas do clone $\mathrm{C} 2$ da casa de sombra para área a pleno sol, nas duas épocas de estudo e no clone $\mathrm{C} 3$, principalmente nas mudas produzidas no inverno. As mudas que tiveram as melhores taxas de sobrevivência foram aquelas produzidas por miniestacas ASR (miniestaca apical sem redução foliar), $\mathrm{AR}_{1 / 3}$ (miniestaca apical com suas folhas reduzidas para 1/3 do tamanho da miniestaca), $\mathrm{AR}_{1 / 2}$ (miniestaca apical com suas folhas reduzidas pela metade) e Afi (Tabela 3 ).

As mudas produzidas no verão apresentaram altura média superior em relação às mudas produzidas no inverno (Tabela 3). As mudas provenientes das miniestacas ASR, $\mathrm{AR}_{1 / 2} \mathrm{e} \mathrm{AR}_{1 / 3}$ mostraram, em geral, resultados superiores em altura, indicando, também, superioridade das miniestacas confeccionadas com $10 \mathrm{~cm}$ de comprimento. Para a característica diâmetro do colo, foi seguida a mesma tendência observada para altura.

Os tipos de miniestacas que proporcionaram maior produção de massa seca seguiram a tendência observada para altura e diâmetro avaliados a pleno sol, destacando-se a não redução das folhas, a redução da metade da folha e a redução de um terço do tamanho da miniestaca. Durante todo o experimento, tanto no verão quanto no inverno, não houve incidência de doenças que comprometessem a produção de mudas. A produção comercial de mudas da empresa consistia na diminuição da metade da área foliar, mas, com os resultados positivos obtidos pela não redução foliar, a empresa conseguiu aumentar a produção diária por pessoa em cerca de $23 \%$, passando de um rendimento operacional de 2.992 miniestacas/pessoa/dia para 3.696 miniestacas/pessoa/ dia, respeitando-se os intervalos de descansos de 10 min a cada hora trabalhada.

\section{DISCUSSÃO}

A resposta diferenciada dos clones aos diferentes padrões de miniestacas e à época do ano para a maioria das características avaliadas se deve, principalmente, à variação entre genótipos (FERREIRA et al., 2004; GOULART; XAVIER, 2008; SANTANA et al., 2010; BORGES et al., 2011).

O alto índice de sobrevivência obtido na saída da casa de vegetação para a maioria dos tipos de miniestacas confirmou os estudos realizados por Wendling e Xavier (2005) e Titon et al. (2003) com Eucalyptus grandis e por Goulart e Xavier (2008) com Eucalyptus grandis x E. urophylla, o que evidencia o adequado controle das condições ambientais (temperatura e umidade) da casa de vegetação (ZUFFELLATO-RIBAS; RODRIGUES, 2001; BORGES et al., 2011).

As raízes observadas na extremidade inferior do tubete são um critério prático utilizado pelos viveiros florestais, como indicativo do momento da retirada

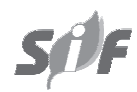

Revista Árvore, Viçosa-MG, v.37, n.1, p.67-77, 2013 
Tabela 2 - Enraizamento na saída da casa de vegetação (ECV) (20 dias após o estaqueamento) e da casa de sombra (ECS) (30 dias após o estaqueamento), sobrevivência na saída da casa de vegetação (SCV) e casa de sombra (SCS) de 12 diferentes padrões de miniestacas no verão e inverno de cinco clones de Eucalyptus grandis x E. urophylla

Table 2 - Rooting at the exit of the greenhouse (ECV) (20 days after the staking) and a shade house (ECS) (30 days after the staking), survival in the exit of greenhouse (SCV) and the shade (SCS) of 12 different patterns offive clones of Eucalyptus grandis x E. urophylla

\begin{tabular}{|c|c|c|c|c|c|c|c|c|c|}
\hline \multirow[t]{2}{*}{ Clone } & \multirow{2}{*}{$\begin{array}{l}\text { Tipos de } \\
\text { miniestacas }\end{array}$} & \multicolumn{4}{|c|}{ Verão } & \multicolumn{4}{|c|}{ Inverno } \\
\hline & & $\operatorname{SCV}(\%)$ & $\operatorname{ECV}(\%)$ & $\operatorname{SCS}(\%)$ & $\operatorname{ECS}(\%)$ & $\operatorname{SCV}(\%)$ & $\operatorname{ECV}(\%)$ & $\operatorname{SCS}(\%)$ & $\operatorname{ECS}(\%)$ \\
\hline \multirow{14}{*}{$\mathrm{C} 1$} & $6 \mathrm{ASR}$ & $100,0 \mathrm{~A}$ & $82,8 \mathrm{~A}$ & $98,4 \mathrm{~A}$ & $92,2 \mathrm{~A}$ & $98,4 \mathrm{~A}$ & $92,2 \mathrm{~A}$ & $93,8 \mathrm{~A}$ & $92,2 \mathrm{~A}$ \\
\hline & $10 \mathrm{ASR}$ & $100,0 \mathrm{~A}$ & $93,8 \mathrm{~A}$ & $98,4 \mathrm{~A}$ & $96,9 \mathrm{~A}$ & $100,0 \mathrm{~A}$ & $86,0 \mathrm{~A}$ & $96,9 \mathrm{~A}$ & $87,5 \mathrm{~A}$ \\
\hline & $6 \mathrm{AR}_{1 / 3}$ & $100,0 \mathrm{~A}$ & $81,3 \mathrm{~A}$ & $98,4 \mathrm{~A}$ & $95,3 \mathrm{~A}$ & $100,0 \mathrm{~A}$ & $84,4 \mathrm{~A}$ & $95,3 \mathrm{~A}$ & $89,1 \mathrm{~A}$ \\
\hline & $10 \mathrm{AR}_{1 / 3}$ & $100,0 \mathrm{~A}$ & $93,8 \mathrm{~A}$ & $100,0 \mathrm{~A}$ & $98,4 \mathrm{~A}$ & $100,0 \mathrm{~A}$ & $87,5 \mathrm{~A}$ & $95,3 \mathrm{~A}$ & $90,6 \mathrm{~A}$ \\
\hline & $6 \mathrm{AR}_{1 / 2}$ & $100,0 \mathrm{~A}$ & $85,9 \mathrm{~A}$ & $100,0 \mathrm{~A}$ & $95,3 \mathrm{~A}$ & $100,0 \mathrm{~A}$ & 79,7A & $93,8 \mathrm{~A}$ & $82,8 \mathrm{~A}$ \\
\hline & $10 \mathrm{AR}_{1 / 2}$ & $100,0 \mathrm{~A}$ & $95,3 \mathrm{~A}$ & $98,4 \mathrm{~A}$ & $95,3 \mathrm{~A}$ & $100,0 \mathrm{~A}$ & $70,4 \mathrm{~A}$ & $89,1 \mathrm{~A}$ & $76,6 \mathrm{~A}$ \\
\hline & $6 \mathrm{Afi}$ & $100,0 \mathrm{~A}$ & $89,1 \mathrm{~A}$ & $100,0 \mathrm{~A}$ & $92,2 \mathrm{~A}$ & $100,0 \mathrm{~A}$ & $82,8 \mathrm{~A}$ & $98,4 \mathrm{~A}$ & $89,1 \mathrm{~A}$ \\
\hline & 10 Afi & $100,0 \mathrm{~A}$ & $81,3 \mathrm{~A}$ & $100,0 \mathrm{~A}$ & $89,1 \mathrm{~A}$ & $100,0 \mathrm{~A}$ & $82,9 \mathrm{~A}$ & $92,2 \mathrm{~A}$ & $84,4 \mathrm{~A}$ \\
\hline & $6 \mathrm{Afs}$ & $95,3 \mathrm{~A}$ & $57,8 \mathrm{~A}$ & $85,9 \mathrm{~A}$ & $70,3 \mathrm{~B}$ & $98,4 \mathrm{~A}$ & $81,3 \mathrm{~A}$ & $93,8 \mathrm{~A}$ & $84,4 \mathrm{~A}$ \\
\hline & 10 Afs & $95,3 \mathrm{~A}$ & $42,2 \mathrm{~B}$ & $84,4 \mathrm{~A}$ & $54,7 \mathrm{~B}$ & $100,0 \mathrm{~A}$ & $92,2 \mathrm{~A}$ & $100,0 \mathrm{~A}$ & $93,8 \mathrm{~A}$ \\
\hline & $6 \mathrm{Asf}$ & $21,9 \mathrm{~B}$ & $0,0 \mathrm{C}$ & $7,8 \mathrm{~B}$ & $1,6 \mathrm{C}$ & $25,0 \mathrm{~B}$ & $3,1 \mathrm{~B}$ & $12,5 \mathrm{~B}$ & $6,3 \mathrm{~B}$ \\
\hline & 10 Asf & $40,6 \mathrm{~B}$ & $0,0 \mathrm{C}$ & $12,5 \mathrm{~B}$ & $3,1 \mathrm{C}$ & $25,0 \mathrm{~B}$ & $0,0 \mathrm{~B}$ & $15,6 \mathrm{~B}$ & $0,0 \mathrm{~B}$ \\
\hline & Média & $87,8 \mathrm{~A}$ & $66,9 A$ & $82,0 A$ & 73,7 & 87,2 & 70,2 & $81,4 A$ & 73,0 \\
\hline & 6 ASR & $100,0 \mathrm{~A}$ & $59,4 \mathrm{~A}$ & $93,8 \mathrm{~A}$ & $82,8 \mathrm{~A}$ & $100,0 \mathrm{~A}$ & $57,8 \mathrm{~A}$ & $98,4 \mathrm{~A}$ & $64,1 \mathrm{~B}$ \\
\hline \multirow{9}{*}{$\mathrm{C} 2$} & $10 \mathrm{ASR}$ & $100,0 \mathrm{~A}$ & $76,6 \mathrm{~A}$ & $96,9 \mathrm{~A}$ & $89,1 \mathrm{~A}$ & $100,0 \mathrm{~A}$ & $78,1 \mathrm{~A}$ & $93,8 \mathrm{~A}$ & $81,3 \mathrm{~A}$ \\
\hline & $6 \mathrm{AR}_{1 / 3}$ & $100,0 \mathrm{~A}$ & $51,6 \mathrm{~A}$ & $98,4 \mathrm{~A}$ & $89,1 \mathrm{~A}$ & $98,4 \mathrm{~A}$ & $25,0 \mathrm{~B}$ & $85,9 \mathrm{~A}$ & $35,9 \mathrm{C}$ \\
\hline & $10 \mathrm{AR}_{1 / 3}^{1 / 3}$ & $100,0 \mathrm{~A}$ & $78,1 \mathrm{~A}$ & $95,3 \mathrm{~A}$ & $85,9 \mathrm{~A}$ & $100,0 \mathrm{~A}$ & $64,1 \mathrm{~A}$ & $93,8 \mathrm{~A}$ & $67,2 \mathrm{~A}$ \\
\hline & $6 \mathrm{AR}_{1 / 2}$ & $92,2 \mathrm{~A}$ & $70,3 \mathrm{~A}$ & $90,6 \mathrm{~A}$ & $76,6 \mathrm{~A}$ & $100,0 \mathrm{~A}$ & $23,4 \mathrm{~B}$ & $98,4 \mathrm{~A}$ & $29,7 \mathrm{C}$ \\
\hline & $10 \mathrm{AR}_{1 / 2}$ & $100,0 \mathrm{~A}$ & $87,5 \mathrm{~A}$ & $100,0 \mathrm{~A}$ & $90,6 \mathrm{~A}$ & $100,0 \mathrm{~A}$ & $53,1 \mathrm{~A}$ & $93,8 \mathrm{~A}$ & $60,9 \mathrm{~B}$ \\
\hline & $6 \mathrm{Afi}$ & $95,3 \mathrm{~A}$ & $62,5 \mathrm{~A}$ & $93,8 \mathrm{~A}$ & $75,0 \mathrm{~A}$ & $100,0 \mathrm{~A}$ & $37,5 \mathrm{~B}$ & $98,4 \mathrm{~A}$ & $48,4 \mathrm{~B}$ \\
\hline & 10 Afi & $89,1 \mathrm{~A}$ & $64,1 \mathrm{~A}$ & $87,5 \mathrm{~A}$ & $67,2 \mathrm{~A}$ & $100,0 \mathrm{~A}$ & $67,2 \mathrm{~A}$ & $96,9 \mathrm{~A}$ & 73,4 \\
\hline & $6 \mathrm{Afs}$ & $85,9 \mathrm{~A}$ & $10,9 \mathrm{~B}$ & $43,8 \mathrm{C}$ & $21,9 \mathrm{~B}$ & $98,4 \mathrm{~A}$ & $17,2 \mathrm{~B}$ & $82,8 \mathrm{~A}$ & $29,7 \mathrm{C}$ \\
\hline & 10 Afs & $93,8 \mathrm{~A}$ & $20,3 \mathrm{~B}$ & $62,5 \mathrm{~B}$ & $25,0 \mathrm{~B}$ & $98,4 \mathrm{~A}$ & $50,0 \mathrm{~A}$ & $89,1 \mathrm{~A}$ & $57,8 \mathrm{~B}$ \\
\hline \multirow{16}{*}{$\mathrm{C} 3$} & $6 \mathrm{Asf}$ & $15,6 \mathrm{~B}$ & $12,5 \mathrm{~B}$ & $0,0 \mathrm{D}$ & $14,1 \mathrm{~B}$ & $28,1 \mathrm{C}$ & $1,6 \mathrm{C}$ & $17,2 \mathrm{~B}$ & $0,0 \mathrm{D}$ \\
\hline & 10 Asf & $23,4 \mathrm{~B}$ & $0,0 \mathrm{~B}$ & $4,7 \mathrm{D}$ & $0,0 \mathrm{~B}$ & $45,3 \mathrm{~B}$ & 1,6 & $\mathrm{C} 25,0 \mathrm{~B}$ & $3,1 \mathrm{D}$ \\
\hline & Média & $82,9 A$ & $49,5 \mathrm{C}$ & $72,3 \mathrm{~B}$ & 59,8 & 89,1 & 39,7 & $81,1 A$ & 46,0 \\
\hline & 6 ASR & $96,9 \mathrm{~A}$ & $64,1 \mathrm{~A}$ & $90,6 \mathrm{~A}$ & $75,0 \mathrm{~B}$ & $100,0 \mathrm{~A}$ & $42,2 \mathrm{~B}$ & $95,3 \mathrm{~A}$ & $51,6 \mathrm{~B}$ \\
\hline & 10 ASR & $100,0 \mathrm{~A}$ & $70,3 \mathrm{~A}$ & $100,0 \mathrm{~A}$ & $89,1 \mathrm{~A}$ & $98,4 \mathrm{~A}$ & $53,1 \mathrm{~A}$ & $92,2 \mathrm{~A}$ & $64,1 \mathrm{~A}$ \\
\hline & $6 \mathrm{AR}_{1 / 3}$ & $100,0 \mathrm{~A}$ & $82,8 \mathrm{~A}$ & $95,3 \mathrm{~A}$ & $87,5 \mathrm{~A}$ & $100,0 \mathrm{~A}$ & $35,9 \mathrm{~B}$ & $93,8 \mathrm{~A}$ & $45,3 \mathrm{~B}$ \\
\hline & $10 \mathrm{AR}_{1 / 3}$ & $100,0 \mathrm{~A}$ & $76,6 \mathrm{~A}$ & $98,4 \mathrm{~A}$ & $100,0 \mathrm{~A}$ & $100,0 \mathrm{~A}$ & $51,6 \mathrm{~A}$ & $95,3 \mathrm{~A}$ & $56,3 \mathrm{~B}$ \\
\hline & $6 \mathrm{AR}_{1 / 2}$ & $100,0 \mathrm{~A}$ & $68,8 \mathrm{~A}$ & $98,4 \mathrm{~A}$ & $89,1 \mathrm{~A}$ & $100,0 \mathrm{~A}$ & $57,8 \mathrm{~A}$ & $100,0 \mathrm{~A}$ & $67,2 \mathrm{~A}$ \\
\hline & $10 \mathrm{AR}_{1 / 2}$ & $100,0 \mathrm{~A}$ & $71,9 \mathrm{~A}$ & $93,8 \mathrm{~A}$ & $92,2 \mathrm{~A}$ & $100,0 \mathrm{~A}$ & $68,8 \mathrm{~A}$ & $100,0 \mathrm{~A}$ & $75,0 \mathrm{~A}$ \\
\hline & $6 \mathrm{Afi}$ & $98,4 \mathrm{~A}$ & $39,1 \mathrm{~B}$ & $95,3 \mathrm{~A}$ & $62,5 \mathrm{~B}$ & $100,0 \mathrm{~A}$ & $34,4 \mathrm{~B}$ & $95,3 \mathrm{~A}$ & $46,9 \mathrm{~B}$ \\
\hline & 10 Afi & $100,0 \mathrm{~A}$ & $46,9 \mathrm{~B}$ & $95,3 \mathrm{~A}$ & $78,1 \mathrm{~B}$ & $100,0 \mathrm{~A}$ & $56,3 \mathrm{~A}$ & $93,8 \mathrm{~A}$ & $68,8 \mathrm{~A}$ \\
\hline & $6 \mathrm{Afs}$ & $92,2 \mathrm{~A}$ & $20,3 \mathrm{C}$ & $78,1 \mathrm{~B}$ & $48,4 \mathrm{C}$ & $95,3 \mathrm{~A}$ & $39,1 \mathrm{~B}$ & $85,9 \mathrm{~A}$ & $50,0 \mathrm{~B}$ \\
\hline & 10 Afs & $89,1 \mathrm{~A}$ & $10,9 \mathrm{C}$ & $62,5 \mathrm{~B}$ & $29,7 \mathrm{C}$ & $98,4 \mathrm{~A}$ & $54,7 \mathrm{~A}$ & $87,5 \mathrm{~A}$ & $64,1 \mathrm{~A}$ \\
\hline & $6 \mathrm{Asf}$ & $25,0 \mathrm{~B}$ & $0,0 \mathrm{C}$ & $3,1 \mathrm{C}$ & $0,0 \mathrm{D}$ & $45,3 \mathrm{~B}$ & $0,0 \mathrm{C}$ & $28,1 \mathrm{~B}$ & $1,6 \mathrm{C}$ \\
\hline & 10 Asf & $18,8 \mathrm{~B}$ & $0,0 \mathrm{C}$ & $4,7 \mathrm{C}$ & $0,0 \mathrm{D}$ & $53,1 \mathrm{~B}$ & $3,1 \mathrm{C}$ & $28,1 \mathrm{~B}$ & $6,3 \mathrm{C}$ \\
\hline & Média & $85,0 A$ & $46,0 \mathrm{C}$ & $76,3 \mathrm{~B}$ & 62,6 & 90,9 & 41,4 & $82,9 A$ & 49,7 \\
\hline \multirow{5}{*}{$\mathrm{C} 4$} & $6 \mathrm{ASR}$ & $100,0 \mathrm{~A}$ & $78,1 \mathrm{~A}$ & $98,4 \mathrm{~A}$ & $85,9 \mathrm{~A}$ & $100,0 \mathrm{~A}$ & $75,0 \mathrm{~A}$ & $98,4 \mathrm{~A}$ & $82,8 \mathrm{~A}$ \\
\hline & $10 \mathrm{ASR}$ & $100,0 \mathrm{~A}$ & $79,7 \mathrm{~A}$ & $100,0 \mathrm{~A}$ & $87,5 \mathrm{~A}$ & $98,4 \mathrm{~A}$ & $85,9 \mathrm{~A}$ & $92,2 \mathrm{~A}$ & $87,5 \mathrm{~A}$ \\
\hline & $6 \mathrm{AR}_{1 / 3}$ & $96,9 \mathrm{~A}$ & $64,1 \mathrm{~A}$ & $96,9 \mathrm{~A}$ & $87,5 \mathrm{~A}$ & $100,0 \mathrm{~A}$ & $84,4 \mathrm{~A}$ & $96,9 \mathrm{~A}$ & $92,2 \mathrm{~A}$ \\
\hline & $10 \mathrm{AR}_{1 / 3}$ & $100,0 \mathrm{~A}$ & $68,8 \mathrm{~A}$ & $93,8 \mathrm{~A}$ & $89,1 \mathrm{~A}$ & $95,3 \mathrm{~A}$ & $62,5 \mathrm{~A}$ & $75,0 \mathrm{~B}$ & $68,8 \mathrm{~A}$ \\
\hline & $6 \mathrm{AR}_{1 / 2}$ & $100,0 \mathrm{~A}$ & $81,3 \mathrm{~A}$ & $100,0 \mathrm{~A}$ & $95,3 \mathrm{~A}$ & $100,0 \mathrm{~A}$ & $84,4 \mathrm{~A}$ & $98,4 \mathrm{~A}$ & $89,1 \mathrm{~A}$ \\
\hline
\end{tabular}

Revista Árvore, Viçosa-MG, v.37, n.1, p.67-77, 2013 
Tabela 2 - Cont.

Table 2 - Cont.

\begin{tabular}{|c|c|c|c|c|c|c|c|c|c|}
\hline \multirow[t]{2}{*}{ Clone } & \multirow{2}{*}{$\begin{array}{l}\text { Tipos de } \\
\text { miniestacas }\end{array}$} & \multicolumn{4}{|c|}{ Verão } & \multicolumn{4}{|c|}{ Inverno } \\
\hline & & $\operatorname{SCV}(\%)$ & $\operatorname{ECV}(\%)$ & $\operatorname{SCS}(\%)$ & $\operatorname{ECS}(\%)$ & $\operatorname{SCV}(\%)$ & $\operatorname{ECV}(\%)$ & $\operatorname{SCS}(\%)$ & $\operatorname{ECS}(\%)$ \\
\hline \multirow{8}{*}{$\mathrm{C} 4$} & $10 \mathrm{AR}_{1 / 2}$ & $95,3 \mathrm{~A}$ & $81,3 \mathrm{~A}$ & $89,1 \mathrm{~A}$ & 79,7A & $100,0 \mathrm{~A}$ & $90,6 \mathrm{~A}$ & $96,9 \mathrm{~A}$ & $92,2 \mathrm{~A}$ \\
\hline & $6 \mathrm{Afi}$ & $96,9 \mathrm{~A}$ & $73,4 \mathrm{~A}$ & $93,8 \mathrm{~A}$ & $82,8 \mathrm{~A}$ & $100,0 \mathrm{~A}$ & $81,3 \mathrm{~A}$ & $96,9 \mathrm{~A}$ & $90,6 \mathrm{~A}$ \\
\hline & 10 Afi & $87,5 \mathrm{~A}$ & 71,9A & $84,4 \mathrm{~A}$ & $79,7 \mathrm{~A}$ & $100,0 \mathrm{~A}$ & $82,8 \mathrm{~A}$ & $98,4 \mathrm{~A}$ & $95,3 \mathrm{~A}$ \\
\hline & $6 \mathrm{Afs}$ & $90,6 \mathrm{~A}$ & $32,8 \mathrm{~B}$ & $84,4 \mathrm{~A}$ & $56,3 \mathrm{~B}$ & $95,3 \mathrm{~A}$ & $82,8 \mathrm{~A}$ & $92,2 \mathrm{~A}$ & $84,4 \mathrm{~A}$ \\
\hline & $10 \mathrm{Afs}$ & $67,2 \mathrm{~B}$ & $34,4 \mathrm{~B}$ & $62,5 \mathrm{~B}$ & $43,8 \mathrm{C}$ & $96,9 \mathrm{~A}$ & $73,4 \mathrm{~A}$ & $87,5 \mathrm{~A}$ & $87,5 \mathrm{~A}$ \\
\hline & $6 \mathrm{Asf}$ & $12,5 \mathrm{C}$ & $0,0 \mathrm{C}$ & $4,7 \mathrm{C}$ & $1,6 \mathrm{D}$ & $9,4 \mathrm{~B}$ & $0,0 \mathrm{~B}$ & $7,8 \mathrm{C}$ & $1,6 \mathrm{~B}$ \\
\hline & $10 \mathrm{Asf}$ & $20,3 \mathrm{C}$ & $1,6 \mathrm{C}$ & $12,5 \mathrm{C}$ & $0,0 \mathrm{D}$ & $20,3 \mathrm{~B}$ & $6,3 \mathrm{~B}$ & $9,4 \mathrm{C}$ & $6,3 \mathrm{~B}$ \\
\hline & Média & $80,6 A$ & $55,6 \mathrm{~B}$ & 76,7B & 65,8 & 84,6 & 67,4 & $79,2 \mathrm{~A}$ & 73,2 \\
\hline \multirow{13}{*}{$\mathrm{C} 5$} & $6 \mathrm{ASR}$ & $100,0 \mathrm{~A}$ & $64,1 \mathrm{~A}$ & $96,9 \mathrm{~A}$ & $90,6 \mathrm{~A}$ & $100,0 \mathrm{~A}$ & $81,3 \mathrm{~A}$ & $96,9 \mathrm{~A}$ & $92,2 \mathrm{~A}$ \\
\hline & 10 ASR & $100,0 \mathrm{~A}$ & $76,6 \mathrm{~A}$ & $96,9 \mathrm{~A}$ & $85,9 \mathrm{~A}$ & $100,0 \mathrm{~A}$ & $84,4 \mathrm{~A}$ & $96,9 \mathrm{~A}$ & $90,6 \mathrm{~A}$ \\
\hline & $6 \mathrm{AR}_{1 / 3}$ & $100,0 \mathrm{~A}$ & $39,1 \mathrm{~B}$ & $98,4 \mathrm{~A}$ & $79,7 \mathrm{~A}$ & $100,0 \mathrm{~A}$ & $46,9 \mathrm{~B}$ & $100,0 \mathrm{~A}$ & 71,9B \\
\hline & $10 \mathrm{AR}_{1 / 3}$ & $100,0 \mathrm{~A}$ & $64,1 \mathrm{~A}$ & $93,8 \mathrm{~A}$ & $68,8 \mathrm{~A}$ & $100,0 \mathrm{~A}$ & $64,1 \mathrm{~B}$ & $92,2 \mathrm{~A}$ & $76,6 \mathrm{~B}$ \\
\hline & $6 \mathrm{AR}_{1 / 2}$ & $100,0 \mathrm{~A}$ & $70,3 \mathrm{~A}$ & $90,6 \mathrm{~A}$ & $90,6 \mathrm{~A}$ & $100,0 \mathrm{~A}$ & $65,6 \mathrm{~B}$ & $100,0 \mathrm{~A}$ & $84,4 \mathrm{~A}$ \\
\hline & $10 \mathrm{AR}_{1 / 2}$ & $92,2 \mathrm{~A}$ & $73,4 \mathrm{~A}$ & $98,4 \mathrm{~A}$ & $92,2 \mathrm{~A}$ & $100,0 \mathrm{~A}$ & $76,6 \mathrm{~A}$ & $98,4 \mathrm{~A}$ & $87,5 \mathrm{~A}$ \\
\hline & $6 \mathrm{Afi}$ & $100,0 \mathrm{~A}$ & $53,1 \mathrm{~A}$ & $100,0 \mathrm{~A}$ & $70,3 \mathrm{~A}$ & $100,0 \mathrm{~A}$ & $71,9 \mathrm{~A}$ & $100,0 \mathrm{~A}$ & $78,1 \mathrm{~B}$ \\
\hline & $10 \mathrm{Afi}$ & $100,0 \mathrm{~A}$ & $68,8 \mathrm{~A}$ & $100,0 \mathrm{~A}$ & $84,4 \mathrm{~A}$ & $100,0 \mathrm{~A}$ & $76,6 \mathrm{~A}$ & $100,0 \mathrm{~A}$ & $87,5 \mathrm{~A}$ \\
\hline & $6 \mathrm{Afs}$ & $70,3 \mathrm{~B}$ & $14,1 \mathrm{C}$ & $50,0 \mathrm{C}$ & $20,3 \mathrm{C}$ & $96,9 \mathrm{~A}$ & $20,3 \mathrm{C}$ & 79,7B & $37,5 \mathrm{C}$ \\
\hline & $10 \mathrm{Afs}$ & $81,3 \mathrm{~B}$ & $31,3 \mathrm{~B}$ & $68,8 \mathrm{~B}$ & $51,6 \mathrm{~B}$ & $95,3 \mathrm{~A}$ & $53,1 \mathrm{~B}$ & $89,1 \mathrm{~B}$ & 60,9B \\
\hline & 6 Asf & $26,6 \mathrm{C}$ & $1,6 \mathrm{C}$ & $18,8 \mathrm{D}$ & $7,8 \mathrm{C}$ & $28,1 \mathrm{C}$ & $0,0 \mathrm{D}$ & $18,8 \mathrm{C}$ & $0,0 \mathrm{D}$ \\
\hline & $10 \mathrm{Asf}$ & $35,9 \mathrm{C}$ & $4,7 \mathrm{C}$ & $17,2 \mathrm{D}$ & $31,3 \mathrm{C}$ & $51,6 \mathrm{~B}$ & $1,6 \mathrm{D}$ & $20,3 \mathrm{C}$ & $4,7 \mathrm{D}$ \\
\hline & Média & 83,9A & $46,7 \mathrm{C}$ & $77,5 \mathrm{~B}$ & 64,5 & 89,3 & 53,5 & $82,7 \mathrm{~A}$ & 64,3 \\
\hline
\end{tabular}

Médias seguidas de uma mesma letra na coluna dentro de cada clone não diferem entre si, pelo teste de Scott-Knott a 5\% de significância.

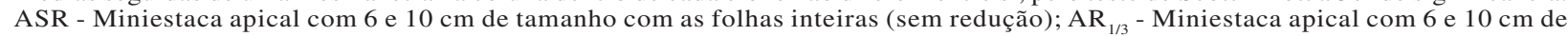
tamanho com suas folhas reduzidas para $1 / 3$ do tamanho da miniestaca; $A_{1 / 2}$ - Miniestaca apical com 6 e $10 \mathrm{~cm}$ de tamanho com suas folhas reduzidas pela metade; Afi - Miniestaca apical com 6 e $10 \mathrm{~cm}$ de tamanho com somente o par de folhas inferiores reduzidas pela metade; Afs - Miniestaca apical com 6 e $10 \mathrm{~cm}$ de tamanho com somente folhas superiores; e Asf - Miniestaca apical com 6 e $10 \mathrm{~cm}$ de tamanho sem as folhas.

das mudas da casa de vegetação para levá-las para a casa de sombra e, posteriormente, para o crescimento a pleno sol. Observou-se que a manutenção das folhas foi importante para o enraizamento em razão, provavelmente, da produção de carboidratos resultantes da fotossíntese e de auxinas produzidas pelas folhas e gemas apicais, essenciais ao enraizamento (HARTMMAN et al., 2011; TAIZ; ZEIGER, 2004; XAVIER et al., 2009). Evidenciouse, com este trabalho, que a manutenção das folhas inferiores na miniestaca favoreceu o enraizamento em relação às folhas superiores em razão, provavelmente, da maior taxa fotossintética proporcionada pela maior área foliar mantida na estaca, apesar de ainda estar com a gema apical, região relacionada à biossíntese de auxina (TAIZ; ZEIGER, 2004).

O maior enraizamento das estacas de $10 \mathrm{~cm}$ pode estar relacionado ao maior número de folhas presentes e maior resistência ao estresse ambiental, conforme verificado por Vendemiatti et al. (2009) em Eucalyptus grandis $\mathrm{x}$ E. resinifera, em que os melhores resultados de enraizamento foram obtidos em miniestacas com quatro pares de folhas. Em espécies lenhosas, a presença de folhas é fundamental para o enraizamento, o que pode ser observado por pesquisas com diferentes estacas de cedro-rosa (XAVIER et al., 2003), açoita-cavalo (PACHECO; FRANCO, 2008) e oliveira (PIO et al., 2005).

A mortalidade observada durante a permanência na casa de sombra se deu, principalmente, naquelas miniestacas que não enraizaram ou que apresentaram sistema radicial pouco desenvolvido na saída da casa de vegetação, resultados semelhantes aos encontrados por Goulart e Xavier (2008) em Eucalyptus grandis Hill x E. urophylla S.T. Blake. Esse fato mostra a importância de se conhecer o tempo ótimo de permanência das miniestacas na casa de vegetação para que ocorra o adequado enraizamento (FERREIRA et al., 2004). 
Tabela 3 - Sobrevivência a pleno sol (SPS), altura (Alt), diâmetro do colo (DC) (50 dias após o estaqueamento), peso de massa seca da parte aérea (PSPA) e peso de massa seca da raiz (PSRA) (61 dias após o estaqueamento) de 12 tipos de miniestacas no verão e inverno de cinco clones de Eucalyptus grandis x E. urophylla.

Table 3 - Survival at full sun (SPS), height (Alt), stem diameter (DC) (50 days after staking), dry weight of shoots (PSPA) and dry weight of root (PSRA) (61 days after staking) of 12 patterns of mini-cuttings in summer and winter of five clones of Eucalyptus grandis $\mathrm{x}$ E. urophylla.

\begin{tabular}{|c|c|c|c|c|c|c|c|c|c|c|c|}
\hline \multirow[t]{2}{*}{ Clone } & \multirow{2}{*}{$\begin{array}{l}\text { Tipos de } \\
\text { miniestacas }\end{array}$} & \multicolumn{5}{|c|}{ Verão } & \multicolumn{5}{|c|}{ Inverno } \\
\hline & & $\begin{array}{l}\text { SPS } \\
(\%)\end{array}$ & $\begin{array}{l}\text { Alt } \\
(\mathrm{cm})\end{array}$ & $\begin{array}{c}\mathrm{DC} \\
(\mathrm{mm})\end{array}$ & $\begin{array}{c}\text { PSPA } \\
(\mathrm{g})\end{array}$ & $\begin{array}{c}\text { PSRA } \\
(\mathrm{g})\end{array}$ & $\begin{array}{l}\text { SPS } \\
(\%)\end{array}$ & $\begin{array}{l}\text { Alt } \\
(\mathrm{cm})\end{array}$ & $\begin{array}{c}\mathrm{DC} \\
(\mathrm{mm})\end{array}$ & $\begin{array}{l}\text { PSPA } \\
(\mathrm{g})\end{array}$ & $\begin{array}{c}\text { PSRA } \\
(\mathrm{g})\end{array}$ \\
\hline \multirow{13}{*}{$\mathrm{C} 01$} & 6 ASR & $95,3 \mathrm{~A}$ & $24,9 \mathrm{~A}$ & $2,8 \mathrm{~A}$ & $0,9 \mathrm{~A}$ & $0,5 \mathrm{~A}$ & $92,2 \mathrm{~A}$ & $18,1 \mathrm{~A}$ & $2,3 \mathrm{~A}$ & $0,6 \mathrm{~A}$ & $0,4 \mathrm{~A}$ \\
\hline & $10 \mathrm{ASR}$ & $93,8 \mathrm{~A}$ & $29,1 \mathrm{~A}$ & $3,0 \mathrm{~A}$ & $1,0 \mathrm{~A}$ & $0,5 \mathrm{~A}$ & $89,1 \mathrm{~A}$ & $19,9 \mathrm{~A}$ & $2,4 \mathrm{~A}$ & $0,7 \mathrm{~A}$ & $0,4 \mathrm{~A}$ \\
\hline & $6 \mathrm{AR}_{1 / 3}$ & $92,2 \mathrm{~A}$ & $23,1 \mathrm{~A}$ & $2,7 \mathrm{~A}$ & $1,1 \mathrm{~A}$ & $0,4 \mathrm{~A}$ & $81,3 \mathrm{~A}$ & $16,1 \mathrm{~A}$ & $2,3 \mathrm{~A}$ & $0,6 \mathrm{~A}$ & $0,3 \mathrm{~A}$ \\
\hline & $10 \mathrm{AR}_{1 / 3}$ & $96,9 \mathrm{~A}$ & $25,2 \mathrm{~A}$ & $2,9 \mathrm{~A}$ & $1,0 \mathrm{~A}$ & $0,5 \mathrm{~A}$ & $92,2 \mathrm{~A}$ & $17,2 \mathrm{~A}$ & $2,2 \mathrm{~A}$ & $0,6 \mathrm{~A}$ & $0,3 \mathrm{~A}$ \\
\hline & $6 \mathrm{AR}_{1 / 2}$ & $98,4 \mathrm{~A}$ & $26,1 \mathrm{~A}$ & $2,7 \mathrm{~A}$ & $1,0 \mathrm{~A}$ & $0,4 \mathrm{~A}$ & $84,4 \mathrm{~A}$ & $13,4 \mathrm{~B}$ & $2,1 \mathrm{~A}$ & $0,5 \mathrm{~A}$ & $0,3 \mathrm{~A}$ \\
\hline & $10 \mathrm{AR}_{1 / 2}$ & $93,8 \mathrm{~A}$ & $27,0 \mathrm{~A}$ & $3,0 \mathrm{~A}$ & $1,2 \mathrm{~A}$ & $0,6 \mathrm{~A}$ & $73,4 \mathrm{~A}$ & $15,4 \mathrm{~B}$ & $2,2 \mathrm{~A}$ & $0,6 \mathrm{~A}$ & $0,3 \mathrm{~A}$ \\
\hline & $6 \mathrm{Afi}$ & $98,4 \mathrm{~A}$ & $22,9 \mathrm{~A}$ & $2,5 \mathrm{~A}$ & $0,9 \mathrm{~A}$ & $0,4 \mathrm{~A}$ & $90,6 \mathrm{~A}$ & $12,3 \mathrm{~B}$ & $1,9 \mathrm{~A}$ & $0,4 \mathrm{~A}$ & $0,2 \mathrm{~B}$ \\
\hline & $10 \mathrm{Afi}$ & $100,0 \mathrm{~A}$ & $22,5 \mathrm{~A}$ & $2,4 \mathrm{~A}$ & $1,0 \mathrm{~A}$ & $0,4 \mathrm{~A}$ & $84,4 \mathrm{~A}$ & $14,6 \mathrm{~B}$ & $2,1 \mathrm{~A}$ & $0,6 \mathrm{~A}$ & $0,3 \mathrm{~B}$ \\
\hline & 6 Afs & $78,1 \mathrm{~B}$ & $22,6 \mathrm{~A}$ & $2,6 \mathrm{~A}$ & $1,0 \mathrm{~A}$ & $0,5 \mathrm{~A}$ & $89,1 \mathrm{~A}$ & $14,5 \mathrm{~B}$ & $2,1 \mathrm{~A}$ & $0,7 \mathrm{~A}$ & $0,4 \mathrm{~A}$ \\
\hline & $10 \mathrm{Afs}$ & $65,6 \mathrm{~B}$ & $20,7 \mathrm{~A}$ & $2,6 \mathrm{~A}$ & $0,9 \mathrm{~A}$ & $0,4 \mathrm{~A}$ & $87,5 \mathrm{~A}$ & $16,6 \mathrm{~A}$ & $2,3 \mathrm{~A}$ & $0,7 \mathrm{~A}$ & $0,3 \mathrm{~A}$ \\
\hline & $6 \mathrm{Asf}$ & $1,6 \mathrm{C}$ & $3,0 \mathrm{~B}$ & $0,5 \mathrm{C}$ & $0,1 \mathrm{~B}$ & $0,1 \mathrm{~B}$ & $3,1 \mathrm{~B}$ & $2,5 \mathrm{C}$ & $0,4 \mathrm{~B}$ & $0,0 \mathrm{~B}$ & $0,0 \mathrm{D}$ \\
\hline & 10 Asf & $9,4 \mathrm{C}$ & $8,8 \mathrm{~B}$ & $1,2 \mathrm{~B}$ & $0,1 \mathrm{~B}$ & $0,1 \mathrm{~B}$ & $7,8 \mathrm{~B}$ & $4,3 \mathrm{C}$ & $0,4 \mathrm{~B}$ & $0,0 \mathrm{~B}$ & $0,1 \mathrm{C}$ \\
\hline & & $77,0 \mathrm{~A}$ & $21,3 \mathrm{~A}$ & $2,4 \mathrm{~A}$ & $\mathbf{0 , 8 A}$ & $0,4 A$ & 72,9 & $13,7 \mathrm{~A}$ & 1,9 & 0,5 & $\mathbf{0 , 3 A}$ \\
\hline \multirow{13}{*}{$\mathrm{C} 02$} & $6 \mathrm{ASR}$ & $73,4 \mathrm{~A}$ & $22,4 \mathrm{~A}$ & $2,7 \mathrm{~A}$ & $1,1 \mathrm{~A}$ & $0,4 \mathrm{~A}$ & $76,6 \mathrm{~A}$ & $15,9 \mathrm{~B}$ & $2,2 \mathrm{~A}$ & $0,9 \mathrm{~A}$ & $0,3 \mathrm{~A}$ \\
\hline & $10 \mathrm{ASR}$ & $73,4 \mathrm{~A}$ & $25,2 \mathrm{~A}$ & $2,8 \mathrm{~A}$ & $1,1 \mathrm{~A}$ & $0,5 \mathrm{~A}$ & $87,5 \mathrm{~A}$ & $19,9 \mathrm{~A}$ & $2,4 \mathrm{~A}$ & $0,9 \mathrm{~A}$ & $0,3 \mathrm{~A}$ \\
\hline & $6 \mathrm{AR}_{1 / 3}$ & $87,5 \mathrm{~A}$ & $20,1 \mathrm{~B}$ & $2,5 \mathrm{~A}$ & $0,8 \mathrm{~A}$ & $0,3 \mathrm{~A}$ & $45,3 \mathrm{~B}$ & $11,4 \mathrm{C}$ & $1,8 \mathrm{~B}$ & $0,6 \mathrm{~B}$ & $0,3 \mathrm{~A}$ \\
\hline & $10 \mathrm{AR}_{1 / 3}^{11 / 3}$ & $81,3 \mathrm{~A}$ & $23,8 \mathrm{~A}$ & $2,8 \mathrm{~A}$ & $1,0 \mathrm{~A}$ & $0,4 \mathrm{~A}$ & $59,4 \mathrm{~B}$ & $18,7 \mathrm{~A}$ & $2,4 \mathrm{~A}$ & $0,8 \mathrm{~A}$ & $0,4 \mathrm{~A}$ \\
\hline & $6 \mathrm{AR}_{1 / 2}^{1 / 3}$ & $71,9 \mathrm{~A}$ & $24,6 \mathrm{~A}$ & $2,6 \mathrm{~A}$ & $1,1 \mathrm{~A}$ & $0,4 \mathrm{~A}$ & $59,4 \mathrm{~B}$ & $11,4 \mathrm{C}$ & $1,8 \mathrm{~B}$ & $0,5 \mathrm{~B}$ & $0,2 \mathrm{~B}$ \\
\hline & $10 \mathrm{AR} 1 / 2$ & $89,1 \mathrm{~A}$ & $26,7 \mathrm{~A}$ & $2,8 \mathrm{~A}$ & $1,1 \mathrm{~A}$ & $0,4 \mathrm{~A}$ & $78,1 \mathrm{~A}$ & $15,9 \mathrm{~B}$ & $2,1 \mathrm{~A}$ & $0,8 \mathrm{~A}$ & $0,3 \mathrm{~A}$ \\
\hline & $6 \mathrm{Afi}$ & $70,3 \mathrm{~A}$ & $18,7 \mathrm{~B}$ & $2,1 \mathrm{~B}$ & $0,8 \mathrm{~A}$ & $0,3 \mathrm{~A}$ & $81,3 \mathrm{~A}$ & $10,8 \mathrm{C}$ & $1,8 \mathrm{~B}$ & $0,4 \mathrm{~B}$ & $0,2 \mathrm{~B}$ \\
\hline & $10 \mathrm{Afi}$ & $76,6 \mathrm{~A}$ & $22,4 \mathrm{~A}$ & $2,7 \mathrm{~A}$ & $1,0 \mathrm{~A}$ & $0,4 \mathrm{~A}$ & $85,9 \mathrm{~A}$ & $15,9 \mathrm{~B}$ & $2,0 \mathrm{~A}$ & $0,7 \mathrm{~A}$ & $0,3 \mathrm{~A}$ \\
\hline & $6 \mathrm{Afs}$ & $25,0 \mathrm{~B}$ & $14,0 \mathrm{~B}$ & $2,0 \mathrm{~B}$ & $0,5 \mathrm{~B}$ & $0,2 \mathrm{~B}$ & $50,0 \mathrm{~B}$ & $10,8 \mathrm{C}$ & $1,9 \mathrm{~B}$ & $0,5 \mathrm{~B}$ & $0,2 \mathrm{~B}$ \\
\hline & 10 Afs & $29,7 \mathrm{~B}$ & $22,4 \mathrm{~A}$ & $2,5 \mathrm{~A}$ & $0,9 \mathrm{~A}$ & $0,4 \mathrm{~A}$ & $73,4 \mathrm{~A}$ & $16,2 \mathrm{~B}$ & $2,1 \mathrm{~A}$ & $0,7 \mathrm{~A}$ & $0,3 \mathrm{~A}$ \\
\hline & $6 \mathrm{Asf}$ & $0,0 \mathrm{C}$ & $0,0 \mathrm{C}$ & $0,0 \mathrm{C}$ & $0,0 \mathrm{C}$ & $0,0 \mathrm{C}$ & $9,4 \mathrm{C}$ & $4,1 \mathrm{D}$ & $0,4 \mathrm{C}$ & $0,1 \mathrm{C}$ & $0,0 \mathrm{C}$ \\
\hline & $10 \mathrm{Asf}$ & $0,0 \mathrm{C}$ & $0,0 \mathrm{C}$ & $0,0 \mathrm{C}$ & $0,0 \mathrm{C}$ & $0,0 \mathrm{C}$ & $12,5 \mathrm{C}$ & $5,2 \mathrm{D}$ & $0,5 \mathrm{C}$ & $0,0 \mathrm{C}$ & $0,0 \mathrm{C}$ \\
\hline & & $56,5 \mathrm{~B}$ & $18,4 \mathrm{~B}$ & $2,1 \mathrm{~B}$ & $\mathbf{0 , 8 A}$ & $0,3 \mathrm{~B}$ & 59,9 & $13,0 A$ & 1,8 & 0,6 & $0,2 \mathrm{~B}$ \\
\hline \multirow{13}{*}{$\mathrm{C} 03$} & $6 \mathrm{ASR}$ & $84,4 \mathrm{~A}$ & $24,9 \mathrm{~A}$ & $2,5 \mathrm{~A}$ & $1,2 \mathrm{~A}$ & $0,4 \mathrm{~A}$ & $59,4 \mathrm{~B}$ & $16,8 \mathrm{~A}$ & $2,0 \mathrm{~A}$ & $0,7 \mathrm{~A}$ & $0,3 \mathrm{~A}$ \\
\hline & $10 \mathrm{ASR}$ & $95,3 \mathrm{~A}$ & $29,9 \mathrm{~A}$ & $2,7 \mathrm{~A}$ & $1,2 \mathrm{~A}$ & $0,5 \mathrm{~A}$ & $65,6 \mathrm{~A}$ & $19,0 \mathrm{~A}$ & $2,0 \mathrm{~A}$ & $0,8 \mathrm{~A}$ & $0,3 \mathrm{~A}$ \\
\hline & $6 \mathrm{AR}_{1 / 3}$ & $90,6 \mathrm{~A}$ & $26,5 \mathrm{~A}$ & $2,6 \mathrm{~A}$ & $1,2 \mathrm{~A}$ & $0,5 \mathrm{~A}$ & $45,3 \mathrm{~B}$ & $11,8 \mathrm{~B}$ & $1,7 \mathrm{~A}$ & $0,5 \mathrm{~B}$ & $0,2 \mathrm{~A}$ \\
\hline & $10 \mathrm{AR}_{1 / 3}^{1 / 3}$ & $89,1 \mathrm{~A}$ & $28,5 \mathrm{~A}$ & $2,7 \mathrm{~A}$ & $1,1 \mathrm{~A}$ & $0,5 \mathrm{~A}$ & $46,9 \mathrm{~B}$ & $16,5 \mathrm{~A}$ & $1,9 \mathrm{~A}$ & $0,5 \mathrm{~B}$ & $0,3 \mathrm{~A}$ \\
\hline & $6 \mathrm{AR}_{1 / 2}^{1 / 3}$ & $95,3 \mathrm{~A}$ & $27,1 \mathrm{~A}$ & $2,5 \mathrm{~A}$ & $1,1 \mathrm{~A}$ & $0,5 \mathrm{~A}$ & $79,7 \mathrm{~A}$ & $14,3 \mathrm{~B}$ & $1,8 \mathrm{~A}$ & $0,7 \mathrm{~A}$ & $0,2 \mathrm{~A}$ \\
\hline & $10 \mathrm{AR}_{1 / 2}$ & $87,5 \mathrm{~A}$ & $29,6 \mathrm{~A}$ & $2,6 \mathrm{~A}$ & $1,4 \mathrm{~A}$ & $0,5 \mathrm{~A}$ & $78,1 \mathrm{~A}$ & $19,1 \mathrm{~A}$ & $2,0 \mathrm{~A}$ & $0,7 \mathrm{~A}$ & $0,3 \mathrm{~A}$ \\
\hline & $6 \mathrm{Afi}$ & $87,5 \mathrm{~A}$ & $23,3 \mathrm{~B}$ & $2,2 \mathrm{~A}$ & $1,0 \mathrm{~B}$ & $0,4 \mathrm{~B}$ & $68,8 \mathrm{~A}$ & $12,5 \mathrm{~B}$ & $1,6 \mathrm{~A}$ & $0,5 \mathrm{~B}$ & $0,2 \mathrm{~A}$ \\
\hline & $10 \mathrm{Afi}$ & $81,3 \mathrm{~A}$ & $25,2 \mathrm{~A}$ & $2,5 \mathrm{~A}$ & $0,8 \mathrm{~B}$ & $0,3 \mathrm{~B}$ & $76,6 \mathrm{~A}$ & $15,7 \mathrm{~A}$ & $1,6 \mathrm{~A}$ & $0,6 \mathrm{~B}$ & $0,2 \mathrm{~A}$ \\
\hline & 6 Afs & $54,7 \mathrm{~B}$ & $20,0 \mathrm{~B}$ & $2,2 \mathrm{~A}$ & $0,9 \mathrm{~B}$ & $0,4 \mathrm{~B}$ & $62,5 \mathrm{~A}$ & $13,7 \mathrm{~B}$ & $1,7 \mathrm{~A}$ & $0,4 \mathrm{~B}$ & $0,2 \mathrm{~A}$ \\
\hline & 10 Afs & $43,8 \mathrm{C}$ & $18,7 \mathrm{~B}$ & $2,0 \mathrm{~A}$ & $0,8 \mathrm{~B}$ & $0,4 \mathrm{~B}$ & $73,4 \mathrm{~A}$ & $16,3 \mathrm{~A}$ & $1,9 \mathrm{~A}$ & $0,5 \mathrm{~B}$ & $0,3 \mathrm{~A}$ \\
\hline & 6 Asf & $1,6 \mathrm{D}$ & $3,1 \mathrm{C}$ & $0,4 \mathrm{~B}$ & $0,1 \mathrm{C}$ & $0,0 \mathrm{C}$ & $6,3 \mathrm{C}$ & $3,8 \mathrm{D}$ & $0,7 \mathrm{~B}$ & $0,0 \mathrm{C}$ & $0,0 \mathrm{~B}$ \\
\hline & $10 \mathrm{Asf}$ & $1,6 \mathrm{D}$ & $3,2 \mathrm{C}$ & $0,4 \mathrm{~B}$ & $0,1 \mathrm{C}$ & $0,1 \mathrm{C}$ & $20,3 \mathrm{C}$ & $8,9 \mathrm{C}$ & $1,0 \mathrm{~B}$ & $0,1 \mathrm{C}$ & $0,1 \mathrm{~B}$ \\
\hline & & $67,7 \mathrm{C}$ & $21,7 \mathrm{~A}$ & $2,1 \mathrm{~B}$ & $\mathbf{0 , 9 A}$ & $0,4 \mathrm{~A}$ & 56,9 & $14,0 \mathrm{~A}$ & 1,6 & 0,5 & $0,2 \mathrm{C}$ \\
\hline \multirow{4}{*}{$\mathrm{C} 04$} & $6 \mathrm{ASR}$ & $95,3 \mathrm{~A}$ & $26,4 \mathrm{~A}$ & $2,6 \mathrm{~A}$ & $1,1 \mathrm{~A}$ & $0,5 \mathrm{~A}$ & $92,2 \mathrm{~A}$ & $15,6 \mathrm{~B}$ & $2,1 \mathrm{~A}$ & $0,6 \mathrm{~A}$ & $0,3 \mathrm{~A}$ \\
\hline & 10 ASR & $95,3 \mathrm{~A}$ & $28,3 \mathrm{~A}$ & $2,6 \mathrm{~A}$ & $1,3 \mathrm{~A}$ & $0,6 \mathrm{~A}$ & $89,1 \mathrm{~A}$ & $20,4 \mathrm{~A}$ & $2,1 \mathrm{~A}$ & $0,6 \mathrm{~A}$ & $0,3 \mathrm{~A}$ \\
\hline & $6 \mathrm{AR}_{1 / 3}$ & $96,9 \mathrm{~A}$ & $24,8 \mathrm{~A}$ & $2,4 \mathrm{~A}$ & $1,1 \mathrm{~A}$ & $0,4 \mathrm{~A}$ & $96,9 \mathrm{~A}$ & $14,9 \mathrm{~B}$ & $1,9 \mathrm{~A}$ & $0,5 \mathrm{~B}$ & $0,3 \mathrm{~A}$ \\
\hline & $10 \mathrm{AR}_{1 / 3}$ & $92,2 \mathrm{~A}$ & $26,4 \mathrm{~A}$ & $2,7 \mathrm{~A}$ & $1,1 \mathrm{~A}$ & $0,4 \mathrm{~A}$ & $68,8 \mathrm{~B}$ & $17,7 \mathrm{~A}$ & $1,9 \mathrm{~A}$ & $0,5 \mathrm{~A}$ & $0,3 \mathrm{~A}$ \\
\hline
\end{tabular}

Revista Árvore, Viçosa-MG, v.37, n.1, p.67-77, 2013 
Tabela 3 - Cont.

Table 3 - Cont.

\begin{tabular}{|c|c|c|c|c|c|c|c|c|c|c|c|}
\hline \multirow[t]{2}{*}{ Clone } & \multirow{2}{*}{$\begin{array}{l}\text { Tipos de } \\
\text { miniestacas }\end{array}$} & \multicolumn{5}{|c|}{ Verão } & \multicolumn{5}{|c|}{ Inverno } \\
\hline & & $\begin{array}{l}\text { SPS } \\
(\%)\end{array}$ & $\begin{array}{l}\text { Alt } \\
(\mathrm{cm})\end{array}$ & $\begin{array}{c}\mathrm{DC} \\
(\mathrm{mm})\end{array}$ & $\begin{array}{c}\text { PSPA } \\
\text { (g) }\end{array}$ & $\begin{array}{c}\text { PSRA } \\
\text { (g) }\end{array}$ & $\begin{array}{l}\text { SPS } \\
(\%)\end{array}$ & $\begin{array}{l}\text { Alt } \\
(\mathrm{cm})\end{array}$ & $\begin{array}{c}\mathrm{DC} \\
(\mathrm{mm})\end{array}$ & $\begin{array}{l}\text { PSPA } \\
\text { (g) }\end{array}$ & $\begin{array}{c}\text { PSRA } \\
(\mathrm{g})\end{array}$ \\
\hline \multirow{9}{*}{$\mathrm{C} 04$} & $6 \mathrm{AR}_{1 / 2}$ & $98,4 \mathrm{~A}$ & $26,2 \mathrm{~A}$ & $2,5 \mathrm{~A}$ & $1,0 \mathrm{~A}$ & $0,5 \mathrm{~A}$ & $95,3 \mathrm{~A}$ & $13,2 \mathrm{~B}$ & $1,7 \mathrm{~A}$ & $0,4 \mathrm{~B}$ & $0,2 \mathrm{~A}$ \\
\hline & $10 \mathrm{AR}_{1 / 2}$ & $85,9 \mathrm{~A}$ & $27,8 \mathrm{~A}$ & $2,5 \mathrm{~A}$ & $1,1 \mathrm{~A}$ & $0,5 \mathrm{~A}$ & $90,6 \mathrm{~A}$ & $19,0 \mathrm{~A}$ & $2,0 \mathrm{~A}$ & $0,7 \mathrm{~A}$ & $0,3 \mathrm{~A}$ \\
\hline & $6 \mathrm{Afi}$ & $90,6 \mathrm{~A}$ & $21,8 \mathrm{~A}$ & $2,2 \mathrm{~A}$ & $1,0 \mathrm{~A}$ & $0,4 \mathrm{~A}$ & $95,3 \mathrm{~A}$ & $12,8 \mathrm{~B}$ & $1,7 \mathrm{~A}$ & $0,4 \mathrm{~B}$ & $0,2 \mathrm{~A}$ \\
\hline & 10 Afi & $82,8 \mathrm{~A}$ & $23,7 \mathrm{~A}$ & $2,4 \mathrm{~A}$ & $0,9 \mathrm{~A}$ & $0,4 \mathrm{~A}$ & $98,4 \mathrm{~A}$ & $16,0 \mathrm{~B}$ & $1,7 \mathrm{~A}$ & $0,5 \mathrm{~B}$ & $0,3 \mathrm{~A}$ \\
\hline & 6 Afs & $75,0 \mathrm{~A}$ & $21,0 \mathrm{~A}$ & $2,4 \mathrm{~A}$ & $1,0 \mathrm{~A}$ & $0,4 \mathrm{~A}$ & $90,6 \mathrm{~A}$ & $15,1 \mathrm{~B}$ & $1,8 \mathrm{~A}$ & $0,5 \mathrm{~A}$ & $0,3 \mathrm{~A}$ \\
\hline & 10 Afs & $51,6 \mathrm{~B}$ & $22,9 \mathrm{~A}$ & $2,3 \mathrm{~A}$ & $1,0 \mathrm{~A}$ & $0,4 \mathrm{~A}$ & $71,9 \mathrm{~B}$ & $16,0 \mathrm{~B}$ & $1,9 \mathrm{~A}$ & $0,5 \mathrm{~B}$ & $0,3 \mathrm{~A}$ \\
\hline & 6 Asf & $4,7 \mathrm{C}$ & $8,5 \mathrm{~B}$ & $1,1 \mathrm{~B}$ & $0,3 \mathrm{~B}$ & $0,1 \mathrm{~B}$ & $6,3 \mathrm{C}$ & $2,9 \mathrm{D}$ & $0,4 \mathrm{C}$ & $0,1 \mathrm{C}$ & $0,0 \mathrm{~B}$ \\
\hline & $10 \mathrm{Asf}$ & $0,0 \mathrm{C}$ & $0,0 \mathrm{C}$ & $0,0 \mathrm{C}$ & $0,0 \mathrm{~B}$ & $0,0 \mathrm{~B}$ & $9,4 \mathrm{C}$ & $7,8 \mathrm{C}$ & $1,0 \mathrm{~B}$ & $0,1 \mathrm{C}$ & $0,1 \mathrm{~B}$ \\
\hline & & $72,4 \mathrm{C}$ & $21,5 \mathrm{~A}$ & $2,1 \mathrm{~B}$ & $\mathbf{0 , 9 A}$ & $\mathbf{0 , 4 A}$ & 75,4 & $14,3 \mathrm{~A}$ & 1,7 & 0,4 & $0,2 \mathrm{C}$ \\
\hline \multirow{13}{*}{$\mathrm{C} 05$} & 6 ASR & $95,3 \mathrm{~A}$ & $27,1 \mathrm{~A}$ & $2,6 \mathrm{~A}$ & $1,2 \mathrm{~A}$ & $0,5 \mathrm{~A}$ & $95,3 \mathrm{~A}$ & $16,6 \mathrm{~B}$ & $2,1 \mathrm{~A}$ & $0,7 \mathrm{~A}$ & $0,3 \mathrm{~A}$ \\
\hline & $10 \mathrm{ASR}$ & $95,3 \mathrm{~A}$ & $28,4 \mathrm{~A}$ & $2,8 \mathrm{~A}$ & $1,3 \mathrm{~A}$ & $0,6 \mathrm{~A}$ & $92,2 \mathrm{~A}$ & $20,1 \mathrm{~A}$ & $2,2 \mathrm{~A}$ & $0,8 \mathrm{~A}$ & $0,3 \mathrm{~A}$ \\
\hline & $6 \mathrm{AR}_{1 / 3}$ & $98,4 \mathrm{~A}$ & $21,6 \mathrm{~B}$ & $2,3 \mathrm{~A}$ & $0,9 \mathrm{~A}$ & $0,4 \mathrm{~A}$ & $87,5 \mathrm{~A}$ & $12,3 \mathrm{C}$ & $1,8 \mathrm{~A}$ & $0,4 \mathrm{~B}$ & $0,2 \mathrm{~B}$ \\
\hline & $10 \mathrm{AR}_{1 / 3}$ & $87,5 \mathrm{~A}$ & $26,3 \mathrm{~A}$ & $2,7 \mathrm{~A}$ & $1,3 \mathrm{~A}$ & $0,5 \mathrm{~A}$ & $79,7 \mathrm{~A}$ & $15,3 \mathrm{~B}$ & $2,0 \mathrm{~A}$ & $0,6 \mathrm{~B}$ & $0,3 \mathrm{~A}$ \\
\hline & $6 \mathrm{AR}_{1 / 2}$ & $85,9 \mathrm{~A}$ & $22,7 \mathrm{~B}$ & $2,5 \mathrm{~A}$ & $1,0 \mathrm{~A}$ & $0,4 \mathrm{~A}$ & $93,8 \mathrm{~A}$ & $13,2 \mathrm{C}$ & $1,8 \mathrm{~A}$ & $0,5 \mathrm{~B}$ & $0,2 \mathrm{~B}$ \\
\hline & $10 \mathrm{AR}_{1 / 2}$ & $98,4 \mathrm{~A}$ & $27,2 \mathrm{~A}$ & $2,7 \mathrm{~A}$ & $1,2 \mathrm{~A}$ & $0,5 \mathrm{~A}$ & $92,2 \mathrm{~A}$ & $18,1 \mathrm{~A}$ & $2,0 \mathrm{~A}$ & $0,7 \mathrm{~A}$ & $0,3 \mathrm{~B}$ \\
\hline & $6 \mathrm{Afi}$ & $98,4 \mathrm{~A}$ & $21,6 \mathrm{~B}$ & $2,4 \mathrm{~A}$ & $1,0 \mathrm{~A}$ & $0,5 \mathrm{~A}$ & $95,3 \mathrm{~A}$ & $11,9 \mathrm{C}$ & $1,8 \mathrm{~A}$ & $0,5 \mathrm{~B}$ & $0,2 \mathrm{~B}$ \\
\hline & $10 \mathrm{Afi}$ & $100,0 \mathrm{~A}$ & $23,6 \mathrm{~B}$ & $2,4 \mathrm{~A}$ & $1,1 \mathrm{~A}$ & $0,4 \mathrm{~A}$ & $95,3 \mathrm{~A}$ & $15,4 \mathrm{~B}$ & $2,0 \mathrm{~A}$ & $0,7 \mathrm{~A}$ & $0,3 \mathrm{~B}$ \\
\hline & $6 \mathrm{Afs}$ & $43,8 \mathrm{C}$ & $11,6 \mathrm{C}$ & $2,0 \mathrm{~B}$ & $0,6 \mathrm{~B}$ & $0,3 \mathrm{~B}$ & $51,6 \mathrm{~B}$ & $12,4 \mathrm{C}$ & $1,7 \mathrm{~A}$ & $0,4 \mathrm{~B}$ & $0,2 \mathrm{~B}$ \\
\hline & 10 Afs & $65,6 \mathrm{~B}$ & $17,6 \mathrm{~B}$ & $2,1 \mathrm{~B}$ & $0,6 \mathrm{~B}$ & $0,3 \mathrm{~B}$ & $82,8 \mathrm{~A}$ & $15,3 \mathrm{~B}$ & $1,9 \mathrm{~A}$ & $0,6 \mathrm{~B}$ & $0,3 \mathrm{~A}$ \\
\hline & 6 Asf & $12,5 \mathrm{D}$ & $3,4 \mathrm{D}$ & $0,3 \mathrm{C}$ & $0,1 \mathrm{C}$ & $0,1 \mathrm{C}$ & $7,8 \mathrm{C}$ & $5,7 \mathrm{D}$ & $0,8 \mathrm{~B}$ & $0,1 \mathrm{C}$ & $0,1 \mathrm{C}$ \\
\hline & 10 Asf & $6,3 \mathrm{D}$ & $6,0 \mathrm{D}$ & $0,5 \mathrm{C}$ & $0,2 \mathrm{C}$ & $0,1 \mathrm{C}$ & $7,8 \mathrm{C}$ & $7,8 \mathrm{D}$ & $0,9 \mathrm{~B}$ & $0,1 \mathrm{C}$ & $0,1 \mathrm{C}$ \\
\hline & & $\mathbf{7 4 , 0 C}$ & $19,8 B$ & $2,1 \mathrm{~B}$ & $\mathbf{0 , 9 A}$ & $\mathbf{0 , 4 A}$ & 73,4 & $13,7 \mathrm{~A}$ & 1,8 & 0,5 & $0,2 \mathrm{C}$ \\
\hline
\end{tabular}

Médias seguidas de uma mesma letra na coluna dentro de cada clone não diferem entre si, pelo teste de Scott-Knott a 5\% de significância. ASR - Miniestaca apical com 6 e $10 \mathrm{~cm}$ de tamanho com as folhas inteiras (sem redução); AR - Miniestaca apical com 6 e $10 \mathrm{~cm}$ de tamanho com suas folhas reduzidas para $1 / 3$ do tamanho da miniestaca; $\mathrm{AR}_{1 / 2}$ - Miniestaca apical com 6 e $10 \mathrm{~cm}$ de tamanho com suas folhas reduzidas pela metade; Afi - Miniestaca apical com 6 e $10 \mathrm{~cm}$ de tamanho com somente o par de folhas inferiores reduzidas pela metade; Afs - Miniestaca apical com 6 e $10 \mathrm{~cm}$ de tamanho com somente folhas superiores; e Asf - Miniestaca apical com 6 e $10 \mathrm{~cm}$ de tamanho sem as folhas.

Os valores encontrados para sobrevivência das mudas produzidas pelas miniestacas $\mathrm{ASR}, \mathrm{AR}_{1 / 2}, \mathrm{AR}_{1 / 3}$ e Afi são considerados dentro da média, de acordo com a produção de mudas dessa espécie/clone nas empresas florestais (80 a 100\% de sobrevivência), bem como estão de acordo também com os resultados de Santana et al. (2010) e Titon et al. (2003) em miniestacas de Eucalyptus urophylla e Eucalyptus grandis, respectivamente.

A altura e diâmetro do colo são características de fácil mensuração, e suas avaliações não são destrutivas, tendo sido utilizados para estimar o padrão de qualidade das mudas nos viveiros florestais. As empresas florestais têm utilizado como critério de qualidade altura média entre 15 e $30 \mathrm{~cm}$ e diâmetro do coleto superior a $2 \mathrm{~mm}$ nas principais espécies de
Eucalyptus plantadas no país (XAVIER et al., 2009). Os padrões de miniestacas diferenciaram a resposta do crescimento em altura, em que as mudas produzidas no verão se enquadram nesses valores de padrão de qualidade de mudas, à exceção das produzidas com as miniestacas Asf e Afi. No inverno, nota-se que as mudas que se enquadram nesse padrão de qualidade são as provenientes de miniestacas confeccionados com $10 \mathrm{~cm}$ de tamanho. Quanto ao diâmetro do colo, no verão, todas as miniestacas com folhas estão dentro do padrão de qualidade estabelecido por esses autores, e somente a miniestaca 6 Afs teve dimensão menor de 2,0 mm nos clones C2 e C5.

As mudas produzidas no inverno tiveram menor crescimento também em diâmetro do colo em razão, provavelmente, da menor temperatura e precipitação, 
fatores que influenciam seu crescimento. A manutenção desses parâmetros de qualidade nas mudas tem sido considerada importante para aumentar a taxa de sobrevivência e de crescimento das plantas no campo (GOMES; PAIVA, 2004).

Neste trabalho, a não redução de folhas, a redução da metade das folhas e a redução de um terço do tamanho da miniestaca proporcionaram maior acúmulo de matéria seca na parte aérea. Trabalhos realizados por Santana et al. (2007) e Santana et al. (2010) com clones de Eucalyptus urophylla mostraram resultados superiores em altura, peso de massa seca da parte aérea e peso de massa seca de raiz para a maioria dos clones estudados, quando mantiveram as folhas inteiras nas miniestacas.

O maior receio de utilizar miniestacas com folhas inteiras seria devido ao maior contato entre as folhas, conciliado com altas temperaturas e umidade no período de verão, que poderiam favorecer a presença de doenças, principalmente, na casa de vegetação (ALFENAS et al., 2009). No entanto, não foram observadas doenças neste trabalho. $\mathrm{O}$ alto índice de sobrevivência nas casas de vegetação e de sombra evidenciou que não houve redução da eficiência da irrigação sobre as miniestacas com folhas inteiras, ou seja, efeito guarda-chuva, e nem transpiração excessiva, confirmando o trabalho realizado por Santana et al. (2010).

A manutenção das folhas inteiras em todos os clones aqui estudados mostrou-se procedimento adequado para produção de mudas clonais de eucalipto, concordando com Santana et al. (2010). As miniestacas ASR, $\mathrm{AR}_{1 / 3}$ e $\mathrm{AR}_{1 / 2}$ apresentaram resultados semelhantes na maioria dos clones é épocas do ano. No entanto, pensando na praticidade operacional e na produtividade, a confecção de miniestacas sem redução (ASF) torna-se procedimento adequando, pois há redução dos movimentos repetitivos para o corte das folhas, conseguindo diminuir os custos com sua produção, uma vez que a confecção de miniestacas é considerada uma das etapas mais onerosas na produção de mudas clonais (LEITE et al., 2005). Apesar de a miniestaca com redução de $1 / 3$ do tamanho da miniestaca ter apresentado resultados positivos de algumas variáveis, ela, em razão da dificuldade e demora em sua confecção, não é uma técnica adequada.

Revista Árvore, Viçosa-MG, v.37, n.1, p.67-77, 2013

\section{CONCLUSÃO}

Diferentes padrões de miniestacas influenciam o enraizamento e sobrevivência das mudas de Eucalyptus grandis x E. urophylla. A manutenção das folhas é importante para o enraizamento e sobrevivência de miniestacas, destacando-se a não redução foliar das miniestacas em razão, principalmente, da praticidade operacional. As mudas produzidas no verão e aquelas confeccionadas com $10 \mathrm{~cm}$ de tamanho apresentaram melhor crescimento.

\section{AGRADECIMENTOS}

Ao Conselho Nacional de Desenvolvimento Científico e Tecnológico (CNPq), pela concessão de bolsas de estudo; e à empresa Celulose Nipo-Brasileira S.A. (Cenibra), pelo apoio financeiro e de infraestrutura.

\section{REFERÊNCIAS}

AlfEnAS, A. C. et al. Clonagem e doenças do Eucalipto. Viçosa, MG: Universidade Federal de Viçosa, 2009. 500p.

ASSIS, T. F.; FETT-NETO, A. G.; ALFENAS, A. C. Current techniques and prospects for the clonal propagation of hardwoods with emphasis on Eucalyptus. In: WALTER, C.; CARSON, M. Plantation forest biotechnology for the 21th century. Kerala, India: Research Signpots, 2004. p.303-333.

BORGES, S. R. et al. Enraizamento de miniestacas de clones híbridos de Eucalyptus globulus. Revista Árvore, v.35, n.3, p.425-434, 2011.

FERREIRA, E. M. et al. Determinação do tempo ótimo do enraizamento de miniestacas de clones de Eucalyptus spp. Revista Árvore, v.28, n.2, p.183-187, 2004.

\section{GOMES, J. M.; PAIVA, H. N. Viveiros}

florestais - propagação sexuada. 3.ed. Viçosa, MG: Universidade Federal de Viçosa, 2004. 116p.

GOULART, P. B.; XAVIER, A. Efeito do tempo de armazenamento de miniestacas no enraizamento de clones de Eucalyptus grandis x E. urophylla.

Revista Árvore, v.32, n.4, p.671-677, 2008.

HARTMANN, H. T. et al. Plant propagation: principles and practices. 8.ed. New York:

Englewood Clipps, 2011. 900p. 
HIGASHI, E. N.; SILVEIRA, R. L. A.; GONÇALVES, A. N. Evolução do jardim clonal de eucalipto para produção de mudas. IPEF, v.24, n.148, PAGINAS, 2000.

LEITE, H. G. et al. Determinação dos custos da qualidade em produção de mudas de eucalipto. Revista Árvore, v.29, n.6, p.955-964, 2005.

NOGUEIRA, A. M. et al. Propagação de figueira (Ficus carica L.) por meio de estacas retiradas durante o período vegetativo. Ciência Agrotécnica, v.31, n.3, p.914-920, 2007.

PACHECO, J. P.; FRANCO, E. T. H. Substratos e estacas com e sem folhas no enraizamento de Luehea divaricata Mart. Ciência Rural, v.38, n.7, p.1900-1906, 2008.

PIO, R. et al. Enraizamento de diferentes tipos de estacas de oliveira (Olea europaea L.) utilizando ácido indolbutírico. Ciência Agrotécnica, v.29, n.3, p.562-567, 2005.

SANTANA, R. C. et al. Influence of leaf area reduction on clonal production of Eucalyptus seedlings. Cerne, v.16, n.3, p.251-257, 2010.

SANTANA, R. C. et al. Influência da área foliar na produção de matéria seca de mudas de miniestacas de eucalipto. In: CONGRESSO BRASILEIRO DE CIÊNCIA DO SOLO, 31., 2007, Gramado. Anais...Gramado: 2007. CD-ROM.
TAIZ, L.; ZEIGER, E. Fisiologia vegetal. 3.ed. Porto Alegre: Artmed, 2004. 719p.

TITON, M. et al. Efeito do AIB no enraizamento de miniestacas e microestacas de clones de Eucalyptus grandis W. Hill ex Maiden. Revista Árvore, v.27, n.1, p.1-7, 2003.

VENDEMIATTI, A. et al. Efeitos da área foliar no enraizamento de miniestacas em híbridos de eucalipto. In: CONGRESSO BRASILEIRO DE FISIOLOGIA VEGETAL, 7., 2009, Fortaleza. Anais... Fortaleza: 2009. 2p.

XAVIER, A.; WENDLING, I.; SILVA, R. L. Silvicultura clonal: princípios e técnicas. Viçosa, MG: Universidade Federal de Viçosa, 2009. 272p.

XAVIER, A.; SANTOS, G. A. S.; OLIVEIRA, M. L. Enraizamento de miniestaca caulinar e foliar na Propagação vegetativa de cedro-rosa (Cedrela fissilis Vell.). Revista Ârvore, v.27, n.3, p.351-356, 2003.

WENDLING, I.; XAVIER, A. Influência do ácido indolbutírico e de miniestaquia seriada no enraizamento e vigor de miniestacas de clones de Eucalyptus grandis. Revista Árvore, v.29, n.6, p.921-930, 2005.

ZUFFELLATO-RIBAS, K. C.; RODRIGUES, J. D. Relações entre épocas do ano e diferentes concentrações de ácido indol-butírico no enraizamento de estacas de Eucalyptus grandis. Boletim de Pesquisa Florestal, n.42, p.71-80, 2001. 
